\title{
Imported and autochthonous kala-azar in France
}

\author{
D Jeannel, P Tuppin, G Brucker, M Danis, M Gentilini
}

Abstract

Objective-To study the epidemiological, clinical, and biological features of imported and autochthonous kala-azar in France.

Design-Prospective survey of all patients in France with kala-azar diagnosed over the two years 1986-7. Information was obtained from parasitology laboratories in regional hospitals and all hospital laboratories and haematology departments capable of diagnosing leishmaniasis in the south of France.

Setting -107 public hospitals in France.

Patients -89 patients with kala-azar.

Interventions-All patients were treated with drugs. In the first instance meglumine antimonate was given to all but two patients.

Main outcome measures-Prevalence of the various clinical and biological features of kala-azar; proportion of patients with HIV infection.

Results - Half (44) of the patients were children under 8 years old. Seventy patients acquired the disease in France. Imported kala-azar was acquired mainly in Mediterranean countries (9/18 cases). Only $46(52 \%)$ of the patients had all three of the classic associated clinical features of fever, splenomegaly, and hepatomegaly. Anaemia was the commonest biological sign, and the association of the four usual biological signs-anaemia, leucopenia, thrombocytopenia, and hypergammaglobulinaemia - was present in only $14(33 \%)$ of the children under 8 and $26(60 \%)$ adults. Fourteen of the patients over 8 years old were infected with HIV.

Conclusion-Doctors must be aware of kala-azar in Mediterranean areas, especially as patients often present without the characteristic features and the disease affects young children preferentially.

\section{Introduction}

Kala-azar, the visceral form of leishmaniasis, is caused by the intracellular protozoa Leishmania donovani and is transmitted by the bite of sandflies belonging to the genus Phlebotomus. The disease is characterised by irregular fever, hepatosplenomegaly, anaemia, leucopenia, hyperglobulinaemia, thrombopenia, and progressive emaciation of the affected host, usually resulting in death when untreated. Kala-azar is endemic in India, northern South America, and the Mediterranean area including the south of France. ${ }^{12}$ Several authors have pointed out that kala-azar is usually considered a tropical disease, and so the endemicity in most areas bordering the Mediterranean is not widely appreciated. ${ }^{34}$ They emphasise the difficulty and delay in making the right diagnosis because of the long incubation period, the non-specific initial symptoms, and the paucity of leishmanial bodies in the marrow aspirate..$^{2-7}$

As in other European countries, the imported disease has not been nationally evaluated in France. Even for southern France, where leishmaniasis and its vectors have been studied ${ }^{28}$ and a canine vaccine has been tested, ${ }^{4}$ there are no detailed data on important series. We studied the different forms of leishmaniasis occurring in France during 1986-7 and report here the epidemiological, clinical, and biological results concerning kala-azar.

\section{Patients and methods}

Collection of information - We recorded the number of cases of visceral and cutaneous leishmaniasis diagnosed in French public hospitals during the two years 1986-7. We requested the participation of all the parasitology laboratories in the regional hospitals, which were expected to deal with most of the cases of leishmaniasis, and hospital laboratories and haematology departments in the south of France which, as leishmaniasis is endemic in this area, can diagnose leishmaniasis. Thus 107 departments were contacted; $69(64 \%)$ participated in the survey, including 34 of the 47 parasitology laboratories.

Inclusion criteria-All of the subjects identified as being infected with leishmania from biopsy samples of the marrow, liver, spleen, and, if present, nodes, either immediately or after culture or inoculation, were included. When leishmania could not be isolated a diagnosis was established by a positive serological test result (immunofluorescence antibody test, enzyme linked immunosorbent assay (ELISA), or another immunological technique) and the presence of biological and clinical features consistent with kalaazar, and favourable response to a specific treatment was considered. Eighty nine patients with kala-azar were identified.

Data and statistical analysis-Forms were filled in for each case under the responsibility of the chiefs of the laboratories with the collaboration of the clinicians in charge of the patients. The following information was requested: age, sex, nationality, place of contracting the infection, methods of diagnosis, clinical and biological features, treatment and outcome, and whether the patient was infected with HIV. An upper limit of 8 years old was fixed for infantile kala-azar. Comparisons were performed by using the $\chi^{2}$ test or Fisher's exact test.

\section{Results}

\section{EPIDEMIOLOGICAL CHARACTERISTICS}

In all, 44 out of the 89 patients were under 8 years old, with a maximum incidence of the disease occurring between the ages of 1 and 4 (table I). Children under 8 comprised 22 males and 22 females and patients over 8, 31 males and 14 females $(p<0 \cdot 07)$.

Table II gives the areas where the disease was contracted and patients' nationality. Seventy subjects contracted the disease in France. Among them, 67 
TABLE III-Presence of clinical and biological features in patients with kala-azar, according to age and immunoefficiency status. Figures are numbers, (percentages)

\begin{tabular}{|c|c|c|c|}
\hline & $\begin{array}{c}\text { Children } \\
<8 \text { years } \\
(\mathrm{n}=44)\end{array}$ & $\begin{array}{c}\text { Patients } \\
>8 \text { years } \\
\text { without HIV } \\
\text { infection } \\
(\mathrm{n}=31)\end{array}$ & $\begin{array}{c}\text { Patients } \\
\text { with HIV } \\
\text { infection } \\
(\mathrm{n}=14)\end{array}$ \\
\hline \multicolumn{4}{|l|}{ Clinical features: } \\
\hline Fever & $41(93)$ & $25(81)$ & $12(86)$ \\
\hline Splenomegaly & $44(100)$ & $25(81)$ & $11(79)$ \\
\hline Hepatomegaly & $25(57)$ & $20(65)$ & $7(50)$ \\
\hline Nodes & $8(18)$ & $9(29)$ & $11(79)$ \\
\hline $\begin{array}{l}\text { Positive on cutaneous } \\
\text { staining }\end{array}$ & & $2(6)$ & \\
\hline \multicolumn{4}{|l|}{ Biological features ${ }^{\star}$ : } \\
\hline Anaemia & $40(93)$ & $27(93)$ & $11(79)$ \\
\hline Thrombocytopenia & $33(77)$ & $22(76)$ & $10(71)$ \\
\hline Hypergammaglobulinaemia & $28(65)$ & $21(72)$ & $10(71)$ \\
\hline Leucopenia & $21(49)$ & $23(79)$ & $12(86)$ \\
\hline
\end{tabular}

*No data available for one patient $<8$ years and two immunocompeten patients $>8$ years.

TABLE IV-Drugs used to treat kala azar in children less than 8 years and patients over 8 years with and without HIV infection

\begin{tabular}{lccc}
\hline Drug & $\begin{array}{c}\text { Patients }>8 \\
\text { years without } \\
\text { HIV infection } \\
(\mathrm{n}=29)\end{array}$ & $\begin{array}{c}\text { Patients with } \\
\text { HIV infection } \\
(\mathrm{n}=13)\end{array}$ \\
\hline $\begin{array}{l}\text { Meglumine antimonate }(\mathrm{n}=44) \\
\text { Meglumine antimonate and pentamidine }\end{array}$ & $23(52)$ & $24(83)$ & $9(69)$ \\
$\begin{array}{l}\text { Meglumine antimonate and other drugs } \\
\text { Meglumine antimonate, pentamidine, and other drugs }\end{array}$ & $11(25)$ & $3(10)$ & $1(8)$ \\
Other drugs alone* & $8(18)$ & $1(3)$ & $2(15)$ \\
& & $1(3)$ & $2(15)$ \\
\hline
\end{tabular}

${ }^{\star}$ Mainly sodium stibogluconate.

were French and three were foreign residents. Of the 19 cases of imported kala-azar, 12 were in French tourists, who contracted the disease mainly in Mediterranean countries (nine in Spain, Greece, or Italy); a woman and her baby contracted the disease in India. The other seven subjects were foreigners who became infected in their country of origin (Algeria); five were under 8 years old.

\section{PATIENTS WITH HIV INFECTION}

Fourteen patients (nine men and five women) were infected with HIV. The proportion of women $(36 \%)$ was higher than for the total number of cases of AIDS in France $(12 \cdot 5 \%, p=0 \cdot 03),{ }^{15}$ but it was not significantly different from the proportion of females with AIDS in the south east of France $(22 \%)$, the area of kala-azar endemicity. ${ }^{15}{ }^{16}$ Nine of the French patients contracted kala-azar in France, two in another European country, and one in India. An Algerian patient contracted kalaazar in Algeria, and no information was available for one case.

FREQUENCIES OF CLINICAL AND BIOLOGICAL FEATURES

Two clinical signs-fever and splenomegaly-were observed in more than $80 \%$ of the patients, whatever their age or HIV status (table III). Splenomegaly was present in all children under 8 and seemed less common among older patients. Hepatomegaly could be seen in $52(58 \%)$ of the cases. Nodes were observed in only $17(23 \%)$ of the patients without HIV infection, independent of their age. The high incidence of nodes among the patients with HIV infection was, of course, non-specific of kala-azar. Positive results on cutaneous staining were rare.

Among the biological signs observed in all patients anaemia was the most common (78, $91 \%$ of patients). Thrombocytopenia was present in $65(76 \%)$ of the patients, independent of age and HIV status. Hypergammaglobulinaemia was not always present. Leucopenia was significantly less common among children under 8 than among older subjects $(\mathrm{p}<0 \cdot 01)$.

Three children under 8 , six patients over 8 without HIV infection, and two patients with HIV infection had no fever. Splenomegaly was absent in six patients over 8 without HIV infection.

About half of the patients (46/89) had the three associated major clinical features-that is, fever, splenomegaly, and hepatomegaly; the proportions were the same among children under 8 and patients over 8 without HIV infection. Presence of all four biological features was less common in children under $8(14 / 43 ; 33 \%)$ than in older subjects $(26 / 43 ; 60 \%)$ $(\mathrm{p}<0.02)$.

Two subjects with isolated clinical signs had only splenomegaly, associated with anaemia and hypergammaglobulinaemia. One patient with HIV infection had no clinical feature of kala-azar except nodes. Six patients had isolated anaemia associated with fever and other clinical signs. The other two patients with isolated biological signs, one with leucopenia and one with thrombocytopenia, showed the three major clinical features. Leucopenia was strongly associated with thrombocytopenia in children and adults ( $\mathrm{p}<0.002$ and $\mathrm{p}<0.001$ respectively). Regarding the clinical signs, no particular association was apparent.

\section{TREATMENT AND OUTCOME}

Meglumine antimonate was given to all of the patients except two (table IV); pentamidine and other drugs, particularly sodium stibogluconate, were not used at first. Nearly half of the children under 8 required further treatment with a drug other than a pentavalent antimonial drug, but only four $(13 \%)$ older patients without HIV infection required a further drug $(p<0.01)$. The outcome was favourable in all of the patients without HIV infection. Five of the 14 patients with HIV infection were not cured of kala-azar.

\section{Discussion}

This is the first study of kala-azar in France on a national scale, and, as far as we know, there has been no other evaluation of imported kala-azar in nonendemic countries. Seventy nine per cent of the patients contracted the disease in France. About half of them were children under 8 years old. A large proportion of the imported cases of kala-azar were acquired in countries in the Mediterranean area. Our study also confirms that kala-azar, acquired mainly in Europe, is an opportunistic infection in AIDS. ${ }^{10}$

Only half of the patients showed the classic associated clinical features of fever, splenomegaly, and hepatomegaly." Though most of the patients were anaemic, the association of the four usual biological signs - that is, anaemia, leucopenia, thrombocytopenia, and hypergammaglobulinaemia - was seen in only $33 \%$ of the children under 8 and $60 \%$ of adults. These results underline the difficulty of making a diagnosis as pointed out in several other reports of imported kala-azar. ${ }^{2-4}$

Pentavalent antimonial drugs have been the reference treatment for kala-azar for more than 40 years. They are potentially toxic, but the alternative treatments, pentamidine and amphotericin $\mathrm{B}$, are also associated with toxicity. ${ }^{12}{ }^{13}$ Furthermore, pentavalent antimonial drugs have failed in up to $15 \%$ of the patients, so there is a need for new treatments, especially as associated HIV infection seems to increase the risk of treatment failing. In our series, nearly half of the children under 8 received a pentavalent antimonial drug and another drug, and several of the patients with HIV infection were not cured of kala-azar. Recently, Badaro et al reported that a combination of pentavalent antimony and interferon gamma can cure some seriously ill patients with refractory or previously untreated kala-azar. ${ }^{14}$

The number of cases of kala-azar reported here probably reflects a large part of the total seen in France 
during the two years, as patients with the disease are generally treated in hospital and biological evidence of the disease is needed. This study provides a good representation of the patterns of the disease in France, with its autochthonous and imported cases.

In conclusion, kala-azar is present in the Mediterranean area, notably in southern France, and doctors must be aware of this, especially because, as our study showed, patients often present with not all of the classic clinical and biological features. Young children are especially at risk, and their disease is often not completely cured after a first course of pentavalent antimonial drugs. Studies on imported leishmaniasis are scarce, but, with the development of tourism and other forms of exchange with countries with a high endemicity of kala-azar, it would be useful for public health authorities to emphasise the risk of contamination, particularly in the Mediterranean area. ${ }^{17}$

We thank all the chiefs of hospital departments of parasitology, haematology, and biology, and their teams, who have kindly sent the data for this national survey. The study was supported by the National Department of Health, Office of Communicable Diseases, France.

1 World Health Organisation. Leishmaniasis. WHO Tech Rep Ser 1984; No 701. 2 Quilici M, Dunan S, Dumont H, et al. Le kala-azar méditerranéen infantile dans le sud-est de la France. Ann Pediatr (Paris) 1987;34:369-73.

3 Hill FGH, Letsky E. Infantile kala-azar in Britain. BMF 1975;iii:334-5.
+ Wheatley T, Sacks S, Flemans RJ, Rubenstein D. Visceral leishmaniasis: a rare imported disease. I Infect 1983;7:166-7.

5 Kinmond S, Galea P, Simpson EM, Parida SK, Goel KM. Kala-azar in a Scottish child. Lancet 1989;ii:325.

6 Pugin P, Miescher PA. Le kala-azar, étude clinique et physiopathologique à propos d'un nouveau cas observé en Suisse. Schweiz Med Wochenschr 1968;93:1320-3.

7 Heilmann K, Dohnert G, Wohlenberg H. Todlich verlaufende leishmaniasis visceralis (kala-azar) bei Mittelmeerurlaubern. Dtsch Med Wochenschr 1971;96:36-8.

8 Ogunkolade BW, Vouldoukis I, Frommel D, Davoust B, Rhodes-Feuillette $A$, Monjour L. Immunisation of dogs with Leishmania infantum-derived vaccine. Vet Parasitol 1988:28:33-41.

9 Killick-Kendrick R, Rioux JA, Bailly M, et al. Ecology of leishmaniasis in the south of France. II Dispersal of Phlebotomus arisasy Tonnoir 1921 as a factor of the spread of visceral leishmaniasis in the Cevennes. Ann Parasitol Hum Comp 1984;59:555-72.

10 Montalban C, Sevilla F, Moreno A, et al. Visceral leishmaniasis: an opportunistic infection in AIDS. F Infect 1987;15:247-50.

11 Rocha H. Leishmania species. In: Mandell G, Douglas RG, Bennett JE, eds. Principles and practice of infectious diseases. New York: Wiley Medical Publication, 1979:2210-8.

12 Bryceson AD, Chulay JD, Mugambi $M$, et al. Visceral leishmaniasis unresponsive to antimonial drugs. II Response to high dosage sodium stibogluconate or prolonged treatment with pentamidine. Trans $R$ Soc Trop Med Hyg 1985;79:705-14.

13 Neva FA. Immunotherapy for parasitic disease. $N$ Engl f Med 1990;322:55-7. 4 Badaro R, Falcoff E, Badaro FS, et al. Treatment of visceral leishmaniasis with pentavalent antimony and interferon gamma. $N$ Engl $f$ Med 1990;322:16-21.

15 Anonymous. Situation du SIDA en France au 31 décembre 1986 [editorial]. Bulletin Epidemiologique Hebdomadaire 1987;7:3-4.

16 Office of Communicable Diseases. Paris: National Department of Health December 1987. (Unpublished.)

17 Jeannel D, Tuppin Ph, Brucker G, Danis M, Gentilini M. Leishmaniasis in France. Lancet 1989;ii:804.

(Accepted 24 May 1991)
Department of

Forensic

Psychiatry, Institute

of Psychiatry,

London

SE5 8AF

John Gunn, FRCPSYCH, professor of forensic psychiatry

Anthony Maden,

MRCPSYCH,

research worker

Mark Swinton,

MRCPSYCH,

research worker

Correspondence to:

Dr Maden.

BMF 1991;303:338-41

\title{
Treatment needs of prisoners with psychiatric disorders
}

\author{
John Gunn, Anthony Maden, Mark Swinton
}

\section{Abstract}

Objective-To describe the prevalence of psychiatric disorder and the treatment needs of sentenced prisoners in England and Wales.

Design-Population survey based on a $5 \%$ sample of men serving prison sentences.

Setting-Sixteen prisons for adult males and nine institutions for male young offenders representative of all prisons in prison type, security levels, and length of sentences.

Subjects -406 young offenders and 1478 adult men, 404 and 1365 of whom agreed to be interviewed.

Main outcome measures-History of psychiatric disorder, clinical diagnosis of psychiatrist, and required treatment.

Results-652 (37\%) men had psychiatric disorders diagnosed, of whom $15(0 \cdot 8 \%)$ had organic disorders, $34(2 \%)$ psychosis, $105(6 \%)$ neurosis, $177(10 \%)$ personality disorder, and $407(23 \%)$ substance misuse. $52(3 \%)$ were judged to require transfer to hospital for psychiatric treatment, $96(5 \%)$ required treatment in a therapeutic community setting, and a further $176(10 \%)$ required further psychiatric assessment or treatment within prison.

Conclusions-By extrapolation the sentenced prison population includes over 700 men with psychosis, and around 1100 who would warrant transfer to hospital for psychiatric treatment. Provision of secure treatment facilities, particularly long term medium secure units, needs to be improved. Services for people with personality, sexual, and substance misuse disorders should be developed in both prisons and the health service.

\section{Introduction}

Staff in our department surveyed sentenced men in the south east prison region in 1972 and found that
$31 \%$ had psychiatric disorders, $2 \%$ of whom were psychotic. ' The survey's results have been quoted as indicating that a third of all prisoners should be in psychiatric hospitals, ${ }^{2}$ but this is not what was found. The survey did not examine the question of treatment in detail, although some men were receiving treatment in prison and many more were reported to be suitable for such treatment, given adequate facilities.

We present the results of a further study that assessed psychiatric need in a 5\% sample of the male sentenced population, which in June 1988 consisted of 28602 men and 8141 male young offenders (aged 17-21 years). ${ }^{3}$ Assessment of cases was expanded to include decisions on appropriate treatment. No standard criteria exist for assessing treatment needs, so needs were decided on clinical grounds for each case; the process was similar to that used to decide on treatment in clinical practice.

\section{Methods}

Sentenced prisoners are held in over 120 institutions, comprising local, training, and open prisons. Institutions are further subdivided according to sentence length and level of security. Sampling all prisons was impractical so we selected 16 prisons containing adult men and nine containing male young offenders. Sampling within each prison was random, and varied from one in two to one in eight prisoners. We had information on the sentence length of inmates of all prisons and on the prison regimens. We selected prisons and sampling rates so that the sample was representative of the total prison population in terms of length of sentence and type of prison.

All inmates chosen were invited to be interviewed, being informed that the survey was confidential and conducted by doctors from outside the prison, that participation was voluntary, and that no individuals would be identified. Interviews were conducted during 